\section{(6) OPEN ACCESS}

\title{
Diagnosis and management of acute lower gastrointestinal bleeding: guidelines from the British Society of Gastroenterology
}

\author{
Kathryn Oakland, ${ }^{\oplus 1}$ Georgina Chadwick, ${ }^{2}$ James E East, ${ }^{3}$ Richard Guy, ${ }^{4}$ \\ Adam Humphries, ${ }^{5}$ Vipul Jairath, ${ }^{6,7}$ Simon McPherson, ${ }^{8}$ Magdalena Metzner, ${ }^{9}$ \\ A John Morris, ${ }^{10}$ Mike F Murphy, ${ }^{11}$ Tony Tham ${ }_{1}{ }^{12}$ Raman Uberoi, ${ }^{13}$ \\ Andrew McCulloch Veitch, ${ }^{14}$ James Wheeler, ${ }^{15}$ Cuthbert Regan ${ }_{1}{ }^{16}$ Jonathan Hoare ${ }^{17}$
}

- Additional material is published online only. To view please visit the journal online (http://dx.doi.org/10.1136/ gutjnl-2018-317807).

For numbered affiliations see end of article.

\section{Correspondence to}

Dr Jonathan Hoare, Department of Gastroenterology, Imperial College Healthcare NHS Trust, London, UK; j.hoare@ic.ac.uk

Received 26 October 2018 Revised 7 January 2019 Accepted 16 January 2019 Published Online First 12 February 2019

\section{Check for updates}

(C) Author(s) (or their employer(s)) 2019. Re-use permitted under CC BY-NC. No commercial re-use. See rights and permissions. Published by BMJ.

To cite: Oakland $\mathrm{K}$, Chadwick G, East JE, et al. Gut 2019;68:776-789.

\section{ABSTRACT}

This is the first UK national guideline to concentrate on acute lower gastrointestinal bleeding (LGIB) and has been commissioned by the Clinical Services and Standards Committee of the British Society of Gastroenterology (BSG). The Guidelines Development Group consisted of representatives from the BSG Endoscopy Committee, the Association of Coloproctology of Great Britain and Ireland, the British Society of Interventional Radiology, the Royal College of Radiologists, NHS Blood and Transplant and a patient representative. A systematic search of the literature was undertaken and the quality of evidence and grading of recommendations appraised according to the GRADE(Grading of Recommendations Assessment, Development and Evaluation) methodology. These guidelines focus on the diagnosis and management of acute LGIB in adults, including methods of risk assessment and interventions to diagnose and treat bleeding (colonoscopy, computed tomography, mesenteric angiography, endoscopic therapy, embolisation and surgery). Recommendations are included on the management of patients who develop LGIB while receiving anticoagulants (including direct oral anticoagulants) or antiplatelet drugs. The appropriate use of blood transfusion is also discussed, including haemoglobin triggers and targets.

\section{FULL LIST OF RECOMMENDATIONS}

1. We suggest that patients presenting with lower gastrointestinal bleeding (LGIB) are stratified as unstable or stable (unstable defined as a shock index $>1$ ). Stable bleeds should then be categorised as major or minor, using a risk assessment tool such as the Oakland score (weak recommendation, moderate quality evidence).

2. We recommend that patients presenting with a minor self-terminating bleed (such as those with an Oakland score $\leq 8$ points), with no other indications for hospital admission can be discharged for urgent outpatient investigation (strong recommendation, moderate quality evidence).

3. We recommend that patients with a major bleed should be admitted to hospital for colonoscopy on the next available list (strong recommendation, moderate quality evidence).

4. We recommend that if a patient is haemodynamically unstable or has a shock index (heart rate/systolic BP) of $>1$ after initial resuscitation and/or active bleeding is suspected, CT angiography provides the fastest and least invasive means to localise the site of blood loss before planning endoscopic or radiological therapy (strong recommendation, low quality evidence).

5. As LGIB associated with haemodynamic instability may be indicative of an upper gastrointestinal bleeding source, we recommend that an upper endoscopy should be performed immediately if no source is identified by initial CT angiography (CTA). If the patient stabilises after initial resuscitation, gastroscopy may be the first investigation (strong recommendation, low quality evidence).

6. Where indicated, catheter angiography with a view to embolisation should be performed as soon as possible after a positive CTA to maximise chances of success. In centres with a $24 / 7$ interventional radiology service, this should be available within $60 \mathrm{~min}$ for haemodynamically unstable patients (strong recommendation, low quality evidence).

7. We recommend that no patient should proceed to emergency laparotomy unless every effort has been made to localise bleeding by radiological and/or endoscopic modalities, except under exceptional circumstances (strong recommendation, low quality evidence).

8. We recommend that in patients who are clinically stable but may need red blood cell (RBC) transfusion, restrictive $\mathrm{RBC}$ thresholds $(\mathrm{Hb}$ trigger $70 \mathrm{~g} / \mathrm{L}$ and a $\mathrm{Hb}$ concentration target of $70-90 \mathrm{~g} / \mathrm{L}$ after transfusion) should be used, unless the patient has a history of cardiovascular disease, in which case a trigger of $80 \mathrm{~g} / \mathrm{L}$ and a target of $100 \mathrm{~g} / \mathrm{L}$ should be used (strong recommendation, low quality evidence).

9. We recommend interrupting warfarin therapy at presentation (weak recommendation, low quality evidence). In cases of unstable gastrointestinal haemorrhage, anticoagulation should be reversed with prothrombin complex 
concentrate and vitamin $\mathrm{K}$ (strong recommendation, moderate quality evidence). For patients with low thrombotic risk, warfarin should be restarted at 7 days after haemorrhage (strong recommendation, low quality evidence).

10. In patients with high thrombotic risk (ie, prosthetic metal heart valve in mitral position, atrial fibrillation with prosthetic heart valve or mitral stenosis, $<3$ months after venous thromboembolism), we recommend that low molecular weight heparin treatment be considered at 48 hours after haemorrhage (strong recommendation, low quality evidence).

11. We suggest that aspirin for primary prophylaxis of cardiovascular events should be permanently discontinued (weak recommendation, low quality evidence).

12. We recommend that aspirin for secondary prevention is not routinely stopped. If it is stopped, it should be restarted as soon as haemostasis is achieved (strong recommendation, moderate quality evidence).

13. We recommend that dual antiplatelet therapy with a P2Y12 receptor antagonist and aspirin is not routinely stopped in patients with coronary stents in situ, and management should be in liaison with a cardiologist (strong recommendation, moderate quality evidence). In unstable haemorrhage we recommend continuing aspirin if the P2Y12 receptor antagonist is interrupted (strong recommendation, moderate quality evidence). P2Y12 receptor antagonist therapy should be reinstated within 5 days (strong recommendation, moderate quality evidence).

14. We recommend interrupting direct oral anticoagulant therapy at presentation (strong recommendation, low quality evidence). We recommend considering treatment with inhibitors such as idarucizumab or andexanet for life-threatening haemorrhage on direct oral anticoagulants (strong recommendation, moderate quality evidence). We suggest restarting direct oral anticoagulant drug treatment at a maximum of 7 days after haemorrhage (weak recommendation, very low quality evidence).

15. All hospitals should have a GI bleeding lead and agreed pathways for the management of acute LGIB (good practice statement).

16. We recommend that all hospitals that routinely admit patients with LGIB should have access to $7 / 7$ on-site colonoscopy and the facilities to provide endoscopic therapy (good practice statement).

17. We recommend that all hospitals that routinely admit patients with LGIB should have access to $24 / 7$ interventional radiology either on site, or via a formalised referral pathway to another hospital (good practice statement).

\section{BACKGROUND}

Lower gastrointestinal bleeding (LGIB) has an estimated incidence of $33-87 / 100000^{12}$ and accounts for 3\% of emergency surgical referrals. ${ }^{3}$ In the United Kingdom, LGIB has been the subject of two recent reviews of care: the National Confidential Enquiry into Patient Outcome and Death (NCEPOD) report entitled Time to get control: a review of the care received by patients who had severe gastrointestinal haemorrhage, and a national comparative audit conducted by NHS Blood and Transplant (NHSBT) and the Association of Coloproctology of Great Britain and Ireland (ACPGBI). ${ }^{4}$ These reports identified deficiencies in the provision of emergency interventions for LGIB. ${ }^{5}$ Notably, only $55 \%$ of hospitals that routinely admitted patients with patients with LGIB were able to provide appropriate 24/7 access to interventional radiology, and $73 \%$ access to $24 / 7$ colonoscopy. ${ }^{4}$

In the UK, in-hospital mortality is $3.4 \%$, although this rises to $18 \%$ in patients who develop LGIB while already hospitalised, ${ }^{6}$ and $20 \%$ in patients with transfusion requirements of $\geq 4$ units of red cells. ${ }^{5}$ Mortality is generally related to comorbidity, not exsanguinating haemorrhage. ${ }^{6}$ The majority of patients with LGIB are admitted to general surgical wards, ${ }^{5}$ and tend to be elderly with a high burden of comorbidity. ${ }^{67}$

After initial resuscitation, the diagnosis and treatment of LGIB remains a challenge for clinicians; identifying the source of bleeding is a clinical priority, and can be challenging in comparison with upper gastrointestinal bleeding (UGIB). Flexible sigmoidoscopy and colonoscopy are the primary investigations, ${ }^{6}$ and can provide a means of endoscopic treatment, although this form of treatment is used in only $2.1 \%$ cases of LGIB in the UK. ${ }^{6}$ Radiological investigations such as general abdominal CT scanning or dedicated CT angiography (CTA) are used in over $25 \%$ of cases. ${ }^{6}$ If extravasation of contrast is shown on CTA, formal, invasive angiography with the option of mesenteric embolisation can be undertaken, although in practice embolisation is used in $<1 \%$ of cases. ${ }^{6}$ Emergency laparotomy for bleeding is very uncommon. ${ }^{5}$ Overall, the most common intervention is red blood cell (RBC) transfusion. ${ }^{4}$

In the UK, the most common cause of LGIB is diverticular bleeding, ${ }^{6}$ although database studies from the USA suggest that prevalence of hospitalisations for diverticular bleeding is decreasing. ${ }^{8}$ Up to $60 \%$ of cases of diverticular bleeding can be classed as severe, ${ }^{9}$ and it is the most common indication for mesenteric embolisation in patients with LGIB. ${ }^{10} 11$ The second most frequent diagnoses are the benign anorectal conditions, such as haemorrhoids, fissures and rectal ulcers. ${ }^{6}$ Significant bleeding from haemorrhoids is generally considered uncommon and brisk LGIB should not be ascribed to haemorrhoids until other causes have been excluded. However, serious haemorrhoidal bleeding is increased in patients with coagulopathy or who are receiving anticoagulants. ${ }^{12}$ Angioectasia can occur at multiple sites within the GI tract, mostly commonly in the caecum. ${ }^{13}$ Rectal proctopathy following pelvic radiotherapy, commonly for prostate cancer or cervical cancer, may present acutely with significant bleeding. Other causes of LGIB include colitis, colorectal cancer and polyps, ${ }^{2}$ but $23 \%$ of patients admitted to hospital with LGIB in the UK are discharged without a diagnosis. ${ }^{6}$

The aims of the guideline are to define standards of care for patients who present acutely with LGIB to UK hospitals, particularly focusing on initial assessment, investigation and haemostatic intervention, the standardisation of care and use of hospital resources. The overall objective is to provide the highest quality care to patients presenting with LGIB.

\section{Scope of the guideline}

The focus of this guideline is the in-hospital management of adult patients presenting with acute LGIB. The management of uncomplicated LGIB in primary care is beyond the scope of this guideline. For this purpose, LGIB refers to patients who present with bright or dark red blood per rectum, clots per rectum or blood mixed in with stool. This guideline is intended to be used by all practitioners who are involved in the hospital care of patients with LGIB. This is the first version of this guideline.

\section{DEVELOPMENT OF THIS GUIDELINE}

The guideline was commissioned by the BSG Clinical Services and Standards Committee and the Endoscopy Section, and 
developed by a multidisciplinary panel of 16 participants comprising gastroenterologists, surgeons and radiologists, following an initial face to face meeting.

The guideline was developed according to the AGREE (Appraisal of Guidelines for REsearch \& Evaluation) methodology. ${ }^{14}$ A guideline commitee was assembled, chaired by $\mathrm{JH}$. Working subgroups with specific areas of expertise were formed to critically appraise the literature supporting the following areas of clinical management: initial assessment, risk stratification and resuscitation (KO, VJ, MFM); medical management (AMV); diagnostic and therapeutic radiology (RU, $\mathrm{SM})$; the exclusion of UGIB and capsule endoscopy (MM); colonoscopy (AH, JEE, AJM); surgery (RG, JW). KO created the first draft of the guideline and all authors critically revised the paper. All recommendations were put to at least two rounds of anonymous voting by all members of the writing group until consensus was reached. The finalised guideline was then circulated to the Association of Coloproctology of Great Britain and Ireland, the Royal College of Radiologists, the British Society of Intervention Radiology, NHS Blood and Transplant, and then peer-reviewed by the BSG via a standardised process. ${ }^{15}$

Evidence supporting the recommendations within this guideline was identified using a systematic literature search of Medline, Embase, CDSR, CENTRAL, DARE, HTA and NHS EED, ClinicalTrials.gov and the WHO International Clinical Trials Registry Platform for articles published between 1997 and December 2017 without language restrictions (details of the search strategy are given in online supplementary appendix 1). Studies published before 1997 were excluded as contemporary management options (such as endoscopic haemostasis) have only been widely adopted in the past 20 years. Studies of adults aged $\geq 16$ years hospitalised with acute LGIB of any cause were eligible. Eligible studies were graded according to the Oxford Centre for Evidence Based Medicine. ${ }^{16}$ Recommendations are categorised according to the GRADE (Grading of Recommendations Assessment, Development and Evaluation) system. ${ }^{17}$

\section{MANAGEMENT ALGORITHM}

1. We suggest that patients presenting with lower GI bleeding are stratified as unstable or stable (unstable defined as a shock index >1). Stable bleeds should then be categorised as major or minor, using a risk assessment tool such as the Oakland score (weak recommendation, moderate quality evidence).

The recommended management of patients presenting with LGIB is described in figure 1. All patients should have routine observations, a full history and examination, including a digital rectal examination, as well as appropriate blood tests. Shock index is calculated by dividing the heart rate by the systolic blood pressure and is a marker of active bleeding. ${ }^{18}$ Its use is well established in the trauma setting, although in patients with massive transfusion requirements. ${ }^{19}$ In UGIB, a study of 215 patients with UGIB showed that the shock index can identify

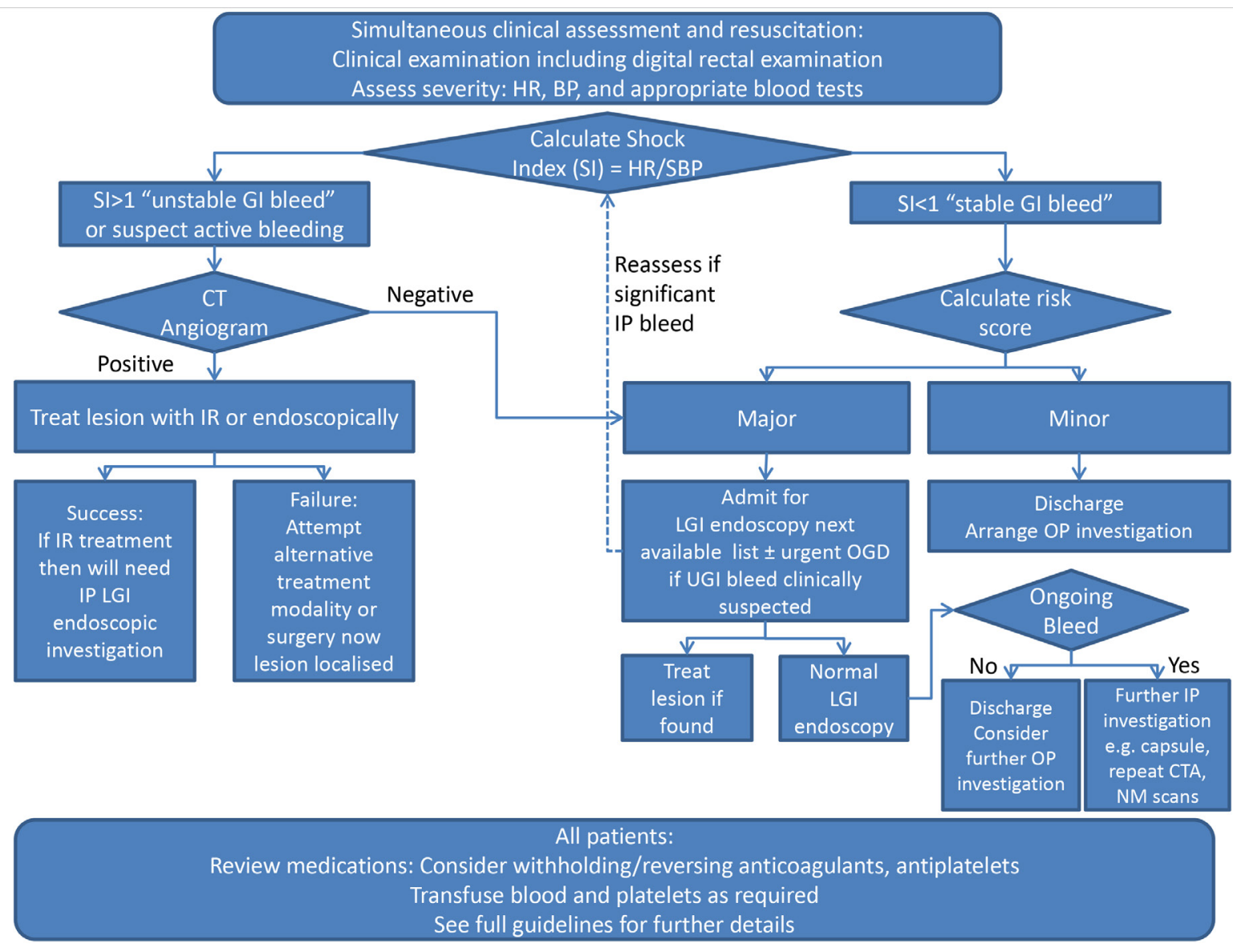

Figure 1 Management algorithm for patients presenting with acute lower gastrointestinal bleeding. Shock index (SI) is calculated by dividing the heart rate (HR) by the systolic blood pressure (SBP). IP, inpatient; IR, interventional radiology; OGD, oesophagogastroduodenoscopy; OP, outpatient; UGI, upper gastrointestinal. 
patients who will require hospital-based intervention. ${ }^{20}$ There are few data describing the use of the shock index in LGIB, although the recent NCEPOD report that included LGIB, found that increasing shock index was associated with mortality. ${ }^{5} \mathrm{~A}$ shock index of $\geq 1$ can also be used to predict extravasation of contrast on angiography in $\mathrm{LGIB}^{21}$ and therefore may be used to identify patients with active bleeding, who are likely to benefit from CTA. As the shock index reflects simply haemodynamic instability and is easy to calculate, its use is warranted even though there are few studies describing its use in LGIB. In patients who are receiving $\beta$ blockade, the shock index should be interpreted with caution. A patient with a shock index $>1$ is classified as having unstable LGIB.

The next management step would be to perform CTA. If there is extravasation of contrast, the source of bleeding can then be treated by embolisation or endoscopic therapy. If a patient has a shock index of $<1$, they are less likely to have active bleeding, and can be classed as a 'stable' LGIB. A stable LGIB can then be risk assessed and classified as a major or minor bleed. A major bleed would benefit from hospital admission, whereas a minor bleed may be suitable for immediate discharge and outpatient investigation.

\section{Risk assessment}

The Oakland score is a risk assessment tool that was derived from a national audit of $\mathrm{LGIB}^{6}$ and can be used to classify stable bleeds as major or minor. It is the first score that has been specifically designed for LGIB and externally validated. ${ }^{22}$ It comprises seven variables that are routinely measured during initial clinical assessment: age, gender, previous hospital admission with LGIB, digital rectal examination findings, heart rate, systolic blood pressure and haemoglobin $(\mathrm{Hb}$, table 1$)$. The score is calculated by summing the individual components. A patient scoring $\leq 8$ points at presentation has a $95 \%$ chance of safe discharge from the emergency department and is therefore classified as a minor bleed. If there are no other indications for hospital admission, a patient scoring $\leq 8$ points can be discharged from the emergency department with outpatient follow-up. Safe discharge is characterised as the absence of all of the following: rebleeding, $\mathrm{RBC}$ transfusion, therapeutic intervention to control bleeding (defined as need for endoscopic, radiological or surgical haemostasis), in-hospital death (all cause) and readmission with further LGIB within 28 days. ${ }^{22}$ A patient scoring $>8$ points is classified as a major bleed, and is likely to benefit from hospital admission. Although the Oakland score is both internally and externally validated, it has not been tested in populations beyond the UK. Additionally, owing to the liberal use of RBC transfusion in the population used to derive the score, ${ }^{6}$ it is likely to under-report the number of patients who can be safely discharged. ${ }^{22}$

In comparison with previously described risk scores for LGIB, the Oakland score has superior ability to identify patients who are at low risk of adverse outcomes. It can also predict rebleeding and the need for RBC transfusion but is inferior at predicting mortality. ${ }^{22}$ The Glasgow-Blatchford score, which was designed for risk stratification in UGIB, ${ }^{23}$ has also been studied in patients with LGIB, and can identify patients at risk of adverse outcomes (rebleeding, need for RBC transfusion, in-hospital death). ${ }^{22}$ It may be clinically useful when assessing the risk of adverse outcomes in patients who it is not safe to discharge.

\section{DIAGNOSIS}

Options for diagnosing the source of bleeding include CTA, catheter mesenteric angiography and lower GI endoscopy, including

\begin{tabular}{|c|c|}
\hline Predictor & Score component value \\
\hline \multicolumn{2}{|l|}{ Age } \\
\hline$<40$ & 0 \\
\hline $40-69$ & 1 \\
\hline$\geq 70$ & 2 \\
\hline \multicolumn{2}{|l|}{ Gender } \\
\hline Female & 0 \\
\hline Male & 1 \\
\hline \multicolumn{2}{|c|}{ Previous LGIB admission } \\
\hline No & 0 \\
\hline Yes & 1 \\
\hline \multicolumn{2}{|l|}{ DRE findings } \\
\hline No blood & 0 \\
\hline Blood & 1 \\
\hline \multicolumn{2}{|l|}{ Heart rate } \\
\hline$<70$ & 0 \\
\hline $70-89$ & 1 \\
\hline 90-109 & 2 \\
\hline$\geq 110$ & 3 \\
\hline \multicolumn{2}{|c|}{ Systolic blood pressure } \\
\hline$<90$ & 5 \\
\hline $90-119$ & 4 \\
\hline $120-129$ & 3 \\
\hline $130-159$ & 2 \\
\hline$\geq 160$ & 0 \\
\hline \multicolumn{2}{|c|}{ Haemoglobin (g/L) } \\
\hline$<70$ & 22 \\
\hline $70-89$ & 17 \\
\hline 90-109 & 13 \\
\hline $110-129$ & 8 \\
\hline 130-159 & 4 \\
\hline$\geq 160$ & 0 \\
\hline
\end{tabular}

Patients scoring $\leq 8$, with no other indications for hospital admission are suitable for immediate discharge from Accident and Emergency and outpatient investigation. DRE, digital rectal examination; LGIB, lower gastrointestinal bleeding.

colonoscopy, flexible sigmoidoscopy and proctoscopy. Radiological or endoscopic studies of the small bowel may also be used if a source of bleeding is not found in the colorectum and has been excluded from the UGI tract.

\section{Diagnosis: colonoscopy, flexible sigmoidoscopy and proctoscopy}

2. We recommend that patients presenting with a minor self-terminating bleed (such as those with an Oakland score $\leq 8$ points), with no other indications for hospital admission can be discharged for urgent outpatient investigation (strong recommendation, moderate quality evidence).

Patients with minor bleeding who are suitable for outpatient investigation should have outpatient colonoscopy. The timing of this depends on clinical urgency and patient choice. However, as $6 \%$ of patients presenting with LGIB have an underlying bowel cancer, ${ }^{24}$ endoscopy within 2 weeks is indicated in higher risk cases. This recommendation is in keeping with NICE guidance that patients aged over 50 with unexplained rectal bleeding should undergo colonoscopy within 2 weeks. $^{25}$ The operational processes required to facilitate this require consideration when implementing this as a local policy. 
In the national audit, benign anorectal conditions accounted for $16.7 \%$ of diagnoses. ${ }^{6}$ Assessment of the anal canal and rectum should therefore be undertaken in all patients presenting with LGIB, using rigid sigmoidoscopy, proctoscopy or flexible endoscopic examination. There are no robust studies directly comparing these modalities; however, the examination must permit the identification of vascular abnormalities, and Dieulafoy ulcers. If performing flexible sigmoidoscopy, useful information about haemorrhoidal disease and low rectal pathology can be obtained using retroflexion (J-manoeuvre).

3. We recommend that patients with a major bleed should be admitted to hospital for colonoscopy on the next available list(strong recommendation, moderate quality evidence).

Colonoscopy has been recommended as the preferred initial investigation in patients classified as a having major or minor bleed, ${ }^{26} 27$ as it has the potential for diagnosis, application of different therapeutic modalities and the ability to mark areas of pathology for potential surgical resection via tattoo injection. Colonoscopy appears to be safe, with no evidence of increased complications compared with other interventions. ${ }^{28-30}$ Studies report diagnostic yields for colonoscopy of 42-90\%. ${ }^{29-33}$ Much of this variation is due to a lack of accepted standardisation in reporting findings and the use of presumed sources of bleeding, such as haemorrhoids and diverticulosis. A much smaller proportion of patients have active bleeding seen at colonoscopy, with resulting therapeutic yields being significantly lower.

There is a lack of evidence comparing colonoscopy with other modalities, including only one randomised controlled trial (RCT) ${ }^{24}$ Green et al randomised 100 patients to either urgent colonoscopy (within 8 hours) or standard care (red cell scanning, catheter angiography or elective colonoscopy) with 50 in each group. While they reported higher diagnostic yields in those randomised to urgent colonoscopy, there were no differences between the two groups in therapeutic yield, length of hospital stay, transfusion requirements, mortality, rebleeding, intensive care admission or requirement for surgery. ${ }^{29}$ This study has major limitations, including a small sample size and a control group that included a mix of elective colonoscopy, red cell scanning or angiography. A retrospective study by Nagata et al evaluated 223 patients hospitalised for LGIB who underwent colonoscopy within 24 hours, 126 of whom had CTA within 3 hours of arrival before proceeding to colonoscopy. ${ }^{34}$ There was no difference in overall diagnostic yield between the groups. However, patients in the CTA/colonoscopy group had a significantly higher diagnostic rate for lesions with active bleeding, adherent clot and visible vessels, and subsequently received more haemostasis, although transfusion requirements and rebleeding rates were not affected. ${ }^{34}$ The recent UK audit of LGIB reported overall diagnostic yields of $71.7 \%$ for colonoscopy and $77.0 \%$ for flexible sigmoidoscopy, although these figures almost certainly represent presumed diagnoses, such as the presence of diverticular disease, as opposed to true stigmata of recent haemorrhage. ${ }^{6}$

As there is no clear evidence for the benefit of colonoscopy over CTA as the initial diagnostic procedure, CTA should be the preferred initial evaluation in patients who are unstable, owing to its speed of access and assessment of the entire GI tract.

\section{Timing of colonoscopy}

The optimum time to perform colonoscopy for acute LGIB remains uncertain. Only one RCT has directly compared urgent ( $<12$ hours) and elective (36-60 hours) colonoscopy in this group of patients. ${ }^{30}$ This trial showed no advantage with urgent colonoscopy for diagnostic or therapeutic yield, length of hospital stay, mortality, transfusion requirements or cost. ${ }^{30}$ Evidence on timing of colonoscopy from observational studies is conflicting and nearly all studies are retrospective. One prospective study, published in abstract form, reported increased diagnostic and therapeutic yields and decreased length of stay with urgent $(<24$ hours) colonoscopy, although there was no mortality benefit. ${ }^{35}$ Four further retrospective studies have also suggested increased therapeutic yield, decreased length of stay and reduced transfusion requirements with urgent ( $<24$ hours) colonoscopy; however, none have shown any benefit in reduced mortality ${ }^{933637}$ and one study reported increased rebleed rates in the urgent group. ${ }^{33}$

In contrast, two retrospective studies have not shown any benefit from urgent colonoscopy. ${ }^{38} 39$ The largest observational study was by Navaneethan et al, who retrospectively analysed 58296 patients admitted with LGIB in the USA using the inpatient care database. ${ }^{37}$ Multivariate analysis showed that early (<24hours) colonoscopy reduced length of stay (2.9 vs 4.6 days), transfusion requirements and costs. However, there was no difference in the proportion undergoing endoscopic therapy and no difference in mortality. ${ }^{37}$ Interestingly, subgroup analysis, limited to patients with a diagnosis of diverticular bleeding, showed no difference in length of stay, mortality or costs with early colonoscopy. ${ }^{37}$ A recent meta-analysis did not demonstrate any significant difference between early and delayed colonoscopy for the important clinical outcomes of rebleeding or RBC transfusion, but colonoscopy performed within 24 hours was found to significantly increase diagnostic and therapeutic yield and reduce the length of stay. ${ }^{24}$ Performing colonoscopy within 24 hours requires significant resources to allow safe, high-quality colonoscopy. Additionally, in many of the studies of timing of colonoscopy, many patients undergoing urgent colonoscopy were unable to tolerate oral bowel preparation, necessitating administration via a nasogastric tube. ${ }^{29} 31$ As there is no clear evidence of benefit with urgent colonoscopy ( $<24$ hours) in patients presenting with acute LGIB, those who require inpatient investigation who do not have active bleeding should have an inpatient colonoscopy on the next available list.

If inpatient colonoscopy is to be performed, then patients should receive bowel preparation to enable adequate mucosal visualisation. There is limited evidence comparing bowel preparation regimens. A retrospective review comparing polyethylene glycol solution with glycerine or water enemas in patients undergoing colonoscopy for LGIB found higher diagnostic yields and reduced need for repeat colonoscopy in the polyethylene glycol group. ${ }^{40}$ A retrospective review of complications in patients receiving bowel preparation in LGIB reported that the most common complications were hypotension and vomiting, although no patient experienced aspiration pneumonia and volume overload. ${ }^{28}$

\section{Diagnosis: radiology}

4. We recommend that if a patient is haemodynamically unstable or has a shock index (heart rate/systolic BP) of $>1$ after initial resuscitation and/or active bleeding is suspected, CT angiography provides the fastest and least invasive means to localise the site of blood loss before planning endoscopic or radiological therapy (strong recommendation, low quality evidence).

CTA has a reported sensitivity of 79-95\% and a specificity of $95-100 \% 0^{41} 42$ in retrospective clinical studies of LGIB. In the national audit the diagnostic yield of CTA was $49.7 \%$, although only 149 patients underwent this investigation. ${ }^{6}$ Experimental 
studies have shown high sensitivity and specificity for the detection of bleeding if the velocity of bleeding is $0.3-1.0 \mathrm{~mL} / \mathrm{min} .{ }^{43} 44$ In keeping with this, retrospective studies have suggested a higher diagnostic yield in haemodynamically unstable patients. ${ }^{45}{ }^{46} \mathrm{CTA}$ should be the first-line investigation in patients with an active LGIB (shock index of $\geq 1$ ), and should be performed in preference to a 'general contrast CT' (performed in the delayed/ portal-venous phase). By definition, all hospitals with access to abdominal CT should be able to perform CTA. CTA is preferred over colonoscopy in unstable patients as it can localise a bleeding source in the UGI tract or small bowel, is widely available, can be rapidly accessed and has no requirement for bowel preparation. As bright or dark red blood per rectum or blood mixed in with stool and haemodynamic instability may be a presentation of UGIB, senior clinical discussion should consider the appropriateness of upper GI endoscopy before proceeding directly to CTA in unstable patients. Bright red rectal bleeding may be indicative of an anorectal source of haemorrhage. Patients with this presentation should undergo direct anorectal inspection. If anoscopy and CTA do not identify the site of bleeding, a full colonoscopy should be performed to allow endoscopic visualisation of the entire lower GI tract.

Where a portal-venous phase scan alone has been performed, it may be beneficial to carry out additional imaging in the arterial phase if the patient continues to bleed. CTA may also be beneficial for preoperative planning before embolisation, surgery or interventional endoscopy. It may be of benefit for patients who have undergone intervention where the bleeding source was not localised or controlled. In patients with renal impairment or contrast allergy, the established guidelines from the Royal College of Radiologists ${ }^{47}$ should be followed.

\section{Diagnosis: excluding an UGI source}

5. As LGIB associated with haemodynamic instability may be indicative of an UGIB source, we recommend that an upper endoscopy should be performed immediately if no source is identified by initial CTA. If the patient stabilises after initial resuscitation, gastroscopy may be the first investigation (strong recommendation, low quality evidence).

As many as $11-15 \%$ of patients suspected initially to have LGIB are ultimately found to have an UGI source. ${ }^{29} 3048$ Findings that are suggestive of an upper GI source of bleeding are brisk rectal bleeding and haemodynamic compromise, a past medical history of peptic ulcer disease, portal hypertension, elevated blood urea/creatinine ratio and patients with risk factors for UGIB, such as the use of antiplatelet drugs. ${ }^{29} 304849$ In patients with high suspicion of UGIB, gastroscopy should be performed after adequate resuscitation if the patient has stabilised. If unstable, we suggest CTA as the first investigation as discussed. The placement of a nasogastric tube in suspected UGIB is not routinely recommended: it does not reliably aid diagnosis, does not affect outcomes and is complicated in up to one-third of patients. ${ }^{5051}$

6. Where indicated, catheter angiography with a view to embolisation should be performed as soon as possible after a positive CTA to maximise chances of success. In centres with a 24/7 interventional radiology service, this should be available within 60 min for baemodynamically unstable patients (strong recommendation, low quality evidence).

Data on the urgency of angiography following a positive CTA or red cell scan are limited to small retrospective studies. ${ }^{5253} \mathrm{~A}$ single-centre retrospective review of 48 cases with a positive CTA scan found that angiograms that were obtained within $90 \mathrm{~min}$ of a positive CTA scan were eight times more likely to identify active bleeding. Any benefit of shorter times to angiography could not be examined as only $17 \%(8 / 48)$ were performed in under $90 \mathrm{~min} .{ }^{53}$ Similarly a case series of 120 patients with LGIB undergoing red cell scanning found that delays in performing angiography were associated with a reduced chance of demonstrating extravasation of contrast on the angiogram. ${ }^{52}$ Embolisation is used to control bleeding in a number of other clinical scenarios, including major trauma, UGIB and post partum haemorrhage. There is existing guidance on the expected response times of interventional radiology (IR) teams-for instance, in major trauma. The 2015 Royal College of Radiologists Standards of Practice recommends that IR teams should be in place within $60 \mathrm{~min}$ of the patient's admission or $30 \mathrm{~min}$ of referral. ${ }^{54}$ The 2016 National Institute for Health and Care Excellence major trauma guideline recognised that while major trauma centre specification required IR access within $60 \mathrm{~min}$, some patients would benefit from shorter times to treatment. ${ }^{55}$ The availability of interventional radiology varies between hospitals. ${ }^{4}$ If formal angiography is to be performed, this should be as soon as possible after a positive CTA to maximise the chance of visualising the bleeding point, thereby allowing treatment. When an on-site embolisation service is provided, it should be available within $60 \mathrm{~min}$ for haemodynamically unstable patients.

\section{Diagnosis: subsequent investigation if no cause of bleeding is found on CTA, lower GI endoscopy or gastroscopy}

A range of additional investigations may be undertaken if imaging, upper and lower GI endoscopy are inconclusive; however, their availability varies between hospitals. Nuclear medicine may offer diagnosis where other investigations, such as CTA, angiography or colonoscopy, are negative, particularly when bleed rates are intermittent or slow. ${ }^{56}$ It offers good but variably reported sensitivity of $60-93 \% .{ }^{57-59} \mathrm{~A}$ single retrospective review of CTA versus red cell scintigraphy showed equal sensitivity but improved anatomical localisation with CTA. ${ }^{56}$ There is no evidence to suggest that repeat CTA may be of benefit, unless bleeding becomes more brisk. Mesenteric angiography is unlikely to be of benefit in the immediate setting, particularly in the haemodynamically stable patient. One retrospective study found that no mesenteric angiograms done within 24 hours of negative CTA were positive. ${ }^{41}$

Video capsule endoscopy (VCE) is a non-invasive investigation that permits examination of the entire length of the small bowel in $79-90 \%$ of patients. ${ }^{60}$ This modality is increasingly used in patients presenting with overt-obscure GI bleeding who have had negative adequate upper and lower GI endoscopy. Three RCTs support the use of VCE in patients with overt-obscure GI bleeding (documented blood loss, no cause found) and no source identified on upper and lower GI endoscopy, reporting a higher diagnostic yield than that of small bowel radiography, catheter angiography and push enteroscopy. ${ }^{61-63}$ In several retrospective and prospective case series the diagnostic yield of VCE has been reported as $50-72 \%$ in patients with obscure overt GI bleeding, with positive findings in more than half of the cases that were negative at CTA or angiography. ${ }^{64-68}$ The diagnostic yield of VCE in patients with overt bleeding appears to be highest when capsule endoscopy is performed as close as possible to the bleeding episode. If it is performed within 48 hours of presentation with bleeding, the diagnostic yield may be as high as $87-91.9 \%,{ }^{69} 70$ but may drop to $<50 \%$ if performed beyond 3 days of presentation..$^{71}$ In patients who have documented overt GI bleeding with negative high-quality 
upper and lower endoscopy, VCE should be the next diagnostic modality. $^{72}$

Limitations of VCE include lack of therapeutic capabilities, inability to control its movement through the GI tract and difficulty in localising the lesion. A primary complication of VCE is capsule retention, occurring in $2 \%$ of patients undergoing evaluation for small bowel bleeding. ${ }^{73}$

\section{THERAPY}

Options for arrest of bleeding include endoscopic therapy, transcatheter mesenteric embolisation and surgery. However, most cases of LGIB will stop spontaneously. ${ }^{6}$ The primary modality for post-polypectomy bleeding is endoscopic therapy.

\section{Therapy: endoscopy}

If urgent colonoscopic therapy is indicated without a known bleeding point, patients can have the colon prepared with a rapid purge using polyethylene glycol electrolyte-based solutions of 4-6 litres over 3-4 hours, which may be delivered by nasogastric tube. ${ }^{29}$ However, blood is a potent laxative and if the bleeding point is known to be in the distal colorectum, for example, post-polypectomy bleed or source identified in CTA, an enema and copious washing may suffice (although the use of an enema alone is described by a small, retrospective, proof of concept study). ${ }^{40} \mathrm{CO}_{2}$ with gas exchange should be used to reduce gas explosion risk in poorly prepared colons, and diathermy or argon plasma coagulation use should be carefully considered.

Endoscopic options for diverticular bleeding at colonoscopy include injection therapy-for example, epinephrine, endoscopic clipping (through- and over-the-scope), thermal therapies such as bipolar coagulation or argon plasma coagulation, and endoscopic band ligation, endoloops or haemostatic powders. All are reported as effective in case reports and case series. ${ }^{24}{ }^{74-77}$ No head-to-head RCTs of endoscopic therapies have been reported. A single retrospective cohort study of 66 patients from Japan compared endoscopic band ligation with endoscopic clipping. ${ }^{77}$ Although, immediate haemostasis was achieved in 100\% of cases with each technique, early rebleeding within 30 days occurred in $6 \%$ of patients with endoscopic band ligation versus $33 \%$ of patients with clipping. ${ }^{76}$ However, endoscopic band ligation requires removal of the scope, after marking the diverticulum with a clip, and then attachment of a banding device before re-intubation and therapy. Through-the-scope clip therapy can be delivered immediately.

As direct head-to-head comparisons between therapeutic modalities are not available for Western populations, ${ }^{24}$ considerations from upper GI experience may potentially guide treatment. Diverticular bleeding occurs above the rectum, and is therefore in the relatively thin-walled colon. Should perforation occur, free perforation is likely. Strategies that minimise the risk of perforation-that is, non-thermal therapies such as clipping, banding or haemostatic sprays $+/$ - adrenaline injection, may be preferred to avoid late diathermy-induced perforation. It seems likely from upper GI experience that if epinephrine is used for haemostasis then a second modality should be applied. ${ }^{3178}$ As through-the-scope clips can apply therapy without the need to remove the scope, are widely available and familiar, and offer very high rates of immediate haemostasis, they are recommended either alone or after epinephrine injection. The use of haemostatic powders-for example, Hemospray (Cook Medical, Winston-Salem, North Carolina, USA), are under investigation in LGIB, ${ }^{24}$ including for bleeding tumours, where they appear effective. $^{79}$ Other methods can be difficult to apply, however, and such sprays are not licensed for use in the lower GI tract in the UK, but are licensed in other countries for this indication.

\section{Post-polypectomy bleeding}

Post-polypectomy bleeding is a discrete source of LGIB. As the source of bleeding is likely to be already known, colonoscopy as opposed to CTA should be the first line of investigation and treatment in patients who are unstable. There is no evidence to support one therapeutic modality over another in the colon for post-polypectomy bleeding; however, extrapolating from the literature on peptic ulcer bleeding in the stomach it is likely that the use of two modalities, epinephrine and one other, is sensible. Heater probe and bipolar diathermy should be used with caution and, if necessary, with reduced energy (see next section, 'Tips for endoscopic therapy in lower GI tract'). Therefore, as for diverticular bleeding, through-the-scope clips are recommended as they are widely available and familiar, either alone or after epinephrine injection. Occasionally an ulcer base related to the polypectomy, may make clips less effective and harder to apply so thermal therapy remains an option. Thermal therapy is also likely to be safer in the thicker-walled rectum below the peritoneal reflection.

\section{Tips for endoscopic therapy in lower Gl tract}

There is often uncertainty among endoscopists as to exact details for volumes of injection, choice of mechanical or thermal therapy and diathermy settings when performing treatment in the LGI tract or small bowel as compared with the UGI tract, with which practitioners generally have more experience. There are few data from RCTs and the availability of haemostatic equipment may vary between units; however, below is some guidance based on the expert opinion of the guideline group and the associated literature review.

- Epinephrine can be injected into the submucosa-for example, quadrantic injection of $1 \mathrm{~mL}$ aliquots of 1:10000 epinephrine around the target to achieve initial haemostasis. 3180

- Caution should be taken when using epinephrine in the rectum to avoid injection into haemorrhoidal vessels which may drain directly into the systemic circulation.

- Through-the-scope clips should be considered first-line treatment for diverticular bleeding as they are widely available, rapid to deploy, low risk and clinically effective. ${ }^{78}$

- For bipolar coagulation use lower power, less pressure and shorter pulses than in the UGI tract-for example, Gold Probe (Boston Scientific) with ERBE VIO 10-15 W, 2s pulses until vessel flattening. ${ }^{2631}$

- Argon plasma coagulation should be used at lower gas flow rates and power-for example, ERBE VIO, $0.8 \mathrm{~L}, 30 \mathrm{~W}^{81} 82$

Practitioners should become familiar with the equipment in their units, and the lead of each unit should ensure that there is relevant LGI-specific local guidance available.

\section{Therapy: embolisation}

If extravasation is demonstrated on angiography, embolisation can be undertaken, although there are no direct head-to-head trials or retrospective studies of embolisation versus endoscopic therapy. Choice of treatment is therefore determined by individual patient factors, local expertise and resource availability.

Embolisation can be performed using coils, liquid agents or particles. The principal agents used are platinum coils, N-butyl cyanoacrylate and polyvinyl alcohol particles. The reported 
technical success rates of embolisation are high, reported at $93-100 \%$, regardless of which embolic agent is used. ${ }^{83-85}$ Bowel ischaemia is the most commonly reported major complication with an incidence of $7-24 \% .{ }^{86-88}$ The risk of rebleeding in the short term after embolisation varies from $10 \%$ to $50 \%{ }^{85} 89-91$ There is a paucity of data on long-term rebleeding rates, but this was reported to be $25 \%$ at 2 years in one retrospective study. ${ }^{92}$

Embolisation may be of benefit where a bleeding site is not seen on CTA, particularly in the setting of malignancy, but must be carefully balanced against a possible increased risk of complications. Evidence from a single retrospective study showed empirical embolisation for tumour bleeding had a clinical success rate of $68 \%$, increasing to $98 \%$ in the context of acute bleeding. ${ }^{93}$ However, a further study including unspecified empiric embolisation showed only a $23 \%$ rebleeding risk but a 30 -day mortality of $31 \%$ versus a mortality of $9 \%$ for embolisation where there was active extravasation. ${ }^{90}$

\section{Therapy: surgery}

7. We recommend that no patient should proceed to emergency laparotomy unless every effort has been made to localise bleeding by radiological and/or endoscopic modalities, except under exceptional circumstances (strong recommendation, low quality evidence).

Laparotomy for acute LGIB is undertaken when endoscopic or radiological interventional measures have failed, ${ }^{6}$ although there are some uncommon instances, such as an aortoenteric fistula, when proceeding directly to surgery may be justified. Proceeding to laparotomy without localisation of the source of the bleeding can be particularly challenging, and given the well-established risk profile of emergency surgery, should be avoided. Emergency subtotal colectomy is an effective and definitive method of treating unlocalised massive LGIB, but its associated morbidity and mortality limits its usefulness. ${ }^{94}$ Even if radiological or endoscopic investigations have been undertaken preoperatively, it is advisable to perform on-table endoscopy after induction of anaesthesia, before proceeding directly to surgery.

In UGIB, the restructuring of surgical services with emergency subspecialisation was associated with reduced mortality for perforated peptic ulceration. Subspecialist experience, intraoperative decision-making, and superior postoperative care have all contributed to this improvement. Surgery should therefore ideally be performed by colorectal surgeons who are able to perform on-table colonoscopy, or in collaboration with medical endoscopists.

Surgery may also be indicated in the management of complications of endoscopic or radiological interventions. A retrospective review of 54 embolised patients reported that surgery was needed for rebleeding or ischaemic complications in 11 cases $(20 \%) .^{11}$

\section{BLOOD TRANSFUSION}

8. We recommend that in patients who are clinically stable but may need RBC transfusion, restrictive RBC thresholds (Hb trigger $70 \mathrm{~g} / \mathrm{L}$ and a $\mathrm{Hb}$ concentration target of $70-90 \mathrm{~g} / \mathrm{L}$ after transfusion) should be used, unless the patient has a history of cardiovascular disease, in which case a trigger of $80 \mathrm{~g} / \mathrm{L}$ and a target of $100 \mathrm{~g} / \mathrm{L}$ should be used (strong recommendation, low quality evidence).

In the 2015 UK audit, 26.7\% patients admitted with LGIB received RBC transfusion at some point during admission, ${ }^{6}$ although the national audit demonstrated that over $80 \%$ of these may be inappropriate or unecessary. ${ }^{4}$ NICE recommends using restrictive $\mathrm{RBC}$ thresholds $(70 \mathrm{~g} / \mathrm{L}$ and a haemoglobin concentration target of 70-90 g/L after transfusion) for patients who need transfusions and who do not have "major haemorrhage", as defined by NICE ${ }^{95}$, or acute coronary syndrome, and that single unit transfusions should be used. ${ }^{95}$ Evidence for the use of restrictive thresholds in LGIB is limited and there are no randomised data.

In UGIB two recent RCTs compared restrictive and liberal RBC transfusion. ${ }^{96}$ One demonstrated increased 6-week survival and reduced rebleeding with a restrictive transfusion policy, although this effect was most notable in patients with cirrhosis and variceal bleeding. ${ }^{97}$ A cluster-randomised pilot study in a UK population of upper GI bleeds showed no improvement in clinical outcomes. ${ }^{98}$ However, a meta-analysis including these RCTs did demonstrate a lower risk of mortality and rebleeding with restrictive transfusion. ${ }^{99}$

Evidence for the use of a restrictive transfusion in patients with cardiovascular disease is less conclusive. A systematic review of patients with coronary artery disease, stroke or peripheral vascular disease hospitalised with critical care needs, UGIB, or orthopaedic or vascular surgery, showed increased risk of myocardial infarction or cardiac arrest in patients allocated to a restrictive threshold. ${ }^{100}$ This is relevant to LGIB given the high prevalence of cardiovascular comorbidities in patients admitted with LGIB. ${ }^{6}$ NICE recommend that for patients with acute coronary syndrome, a RBC threshold of $80 \mathrm{~g} / \mathrm{L}$ and a haemoglobin concentration target of $80-100 \mathrm{~g} / \mathrm{L}$ after transfusion should be used. ${ }^{101}$

In contrast to $\mathrm{RBC}$ transfusion, platelet or fresh frozen plasma (FFP) transfusion is uncommon, and used in only $1.8 \%$ and 2.2\% patients, respectively. ${ }^{6}$ Most of these components are used in major haemorrhage protocols. There are no randomised data comparing platelet or FFP thresholds in patients with LGIB. Randomised data on FFP is limited to prophylaxis of bleeding. ${ }^{102}$ One cohort study of patients undergoing cardiac surgery with excessive perioperative bleeding showed no benefit with FFP transfusion. ${ }^{103}$

\section{DRUG THERAPY CONSIDERATIONS IN ACUTE LGIB}

Anticoagulant and antiplatelet use is common in patients presenting with LGIB. $^{6}$ Most warfarin is pharmacologically reversed ${ }^{4}$ and if managed appropriately, these patients tend not to experience increased rates of rebleeding. ${ }^{6}$ Predominantly the anticoagulant effect of direct oral anticoagulants (DOACs) is managed by simply withholding this medication. No drug can easily reverse the platelet dysfunction seen with antiplatelets, and these agents are mostly withheld in the acute setting of LGIB, ${ }^{6}$ despite evidence of poorer cardiovascular outcomes in the long term. ${ }^{104}$

9. We recommend interrupting warfarin therapy at presentation (weak recommendation, low quality evidence). In cases of unstable gastrointestinal haemorrhage, anticoagulation should be reversed with prothrombin complex concentrate and vitamin $K$ (strong recommendation, moderate quality evidence). For patients with low thrombotic risk, warfarin should be restarted at 7 days after haemorrhage (strong recommendation, low quality evidence).

Warfarin has a long half-life and its anticoagulant effect can persists for 3-5 days after discontinuation of treatment. In the context of GI bleeding, warfarin can be interrupted at presentation. It can be simply discontinued for a low-risk haemorrhage and, in addition, reversed in severe haemorrhage, with vitamin $\mathrm{K}$ and prothrombin complex concentrate if required. ${ }^{105}$ Overall, 
there is a mortality benefit from restarting warfarin once the LGIB has stopped. ${ }^{106-108}$ A large retrospective study of patients with low thrombotic risk examined the optimum time at which to restart warfarin after GI bleeding. ${ }^{106}$ If warfarin was restarted between 7 to 15 days after haemorrhage, thromboembolic events and mortality were reduced with no increase in rebleeding rates. Starting warfarin before this resulted in a twofold increase in rebleeding and a non-significant reduction in thromboembolism. Warfarin should therefore be restarted 7 days after LGIB.

10. In patients with high thrombotic risk (ie, prosthetic metal heart valve in mitral position, atrial fibrillation with prosthetic heart valve or mitral stenosis, $<3$ months after venous thromboembolism), we recommend that low molecular weight heparin therapy be considered at 48 hours after haemorrbage (strong recommendation, low quality evidence).

Bridging of warfarin or DOAC therapy with low molecular weight heparin has not been tested in the setting of acute GI bleeding, but in the elective situation, in patients with low thrombotic risk, there is an increased risk of haemorrhage without reduction in thrombosis. ${ }^{109-111}$ However, in a patient receiving warfarin with high thrombotic risk-for example, with a metal mitral valve, substitution of warfarin with low molecular weight heparin once the patient is haemodynamically stable with a normal international normalised ratio might be beneficial.

In patients who are receiving unfractionated heparin, discontinuation of the drug is usually adequate due to its short halflife, but in severe life-threatening haemorrhage its effects can be reversed with protamine sulfate. The anticoagulant effect of low molecular weight heparin may persist for 24 hours and protamine sulfate is less effective.

11. We suggest that aspirin for primary prophylaxis of cardiovascular events should be permanently discontinued (weak recommendation, low quality evidence).

12. We recommend that aspirin for secondary prevention is not routinely stopped. If it is stopped, it should be restarted as soon as haemostasis is achieved (strong recommendation, moderate quality evidence).

Treatment with antiplatelet agents presents a balance of risk between the beneficial antithrombotic effects versus an increased risk of GI bleeding. Many instances of LGIB cease spontaneously, and others respond to endoscopic, radiological or surgical treatment. A myocardial infarction resulting from discontinuation of antiplatelet therapy in a patient with coronary stents may be fatal, however, and in patients at risk of cerebrovascular disease could result in permanent disability from a stroke. Some patients have relatively low risk indications for antithrombotic therapy and it may be reasonable to discontinue treatment temporarily in the event of LGIB. A recent observational study of patients with LGIB showed that in comparison with patients receiving no antiplatelet or anticoagulant drugs, those receiving a single antiplatelet agent had a threefold increase in rebleeding, although there was no associated increase in interventions to treat bleeding or mortality. ${ }^{112}$

Aspirin irreversibly inhibits the function of platelets for their lifespan (5-7 days). Its effect on endothelial prostaglandin synthesis is, however, much shorter, and there may be benefits in temporarily stopping aspirin if severe haemorrhage occurs. In patients receiving single antiplatelet agents most rebleeding occurs within 5 days of the index event. ${ }^{112}$ The risk: benefit analysis of discontinuing aspirin is dependent on the indication for aspirin and on the severity of haemorrhage. In UGIB, the availability of emergency endoscopy and haemostasis is well established and antiplatelet therapy can be continued in patients with high thrombotic risk. ${ }^{113} 114$ In patients receiving aspirin monotherapy for primary prevention, it may be interrupted on presentation with LGIB with little increase in the risk of thrombosis. ${ }^{112}$ Permanent discontinuation should be considered.

Patients taking aspirin for secondary prevention are at greater risk of thrombosis than those taking it for primary prevention. Studies of patients receiving long-term low-dose aspirin for secondary prevention, have shown that aspirin discontinuation is associated with a threefold increased risk of cardiovascular or cerebrovascular events, 70\% occurring within 7-10 days. ${ }^{115} 116$ An RCT of patients undergoing surgery found that continuing aspirin for secondary prevention was associated with fewer major cardiac events without an increase in haemorrhage. ${ }^{117}$ An RCT of aspirin continuation versus placebo in acute peptic ulcer bleeding found a statistically non-significant difference in the incidence of recurrent bleeding in the aspirin group versus placebo $(10.3 \%$ vs $5 \%, 5.4$ percentage point difference, $95 \% \mathrm{CI}$ -3.6 to 13.4 ) but a significantly reduced all-cause mortality in the aspirin group $(1.3 \%$ vs $12.9 \%, 11.6$ percentage point difference, $95 \%$ CI 3.7 to 19.5$).{ }^{118}$ This was after endoscopic therapy to achieve haemostasis, and all patients received proton pump inhibitor infusions. In LGIB, an observational study of patients receiving single antiplatelet therapy demonstrated no benefit for rebleeding or mortality in withholding the drug for $<5$ days in comparison with continuing it. ${ }^{112}$ We therefore recommend that aspirin for secondary prevention should not be routinely stopped. If it is stopped, it should be restarted as soon as haemostasis is achieved.

13. We recommend that dual antiplatelet therapy with a P2Y12 receptor antagonist and aspirin is not routinely stopped in patients with coronary stents in situ and management should be in liaison with a cardiologist (strong recommendation, moderate quality evidence). In unstable haemorrhage we recommend continuing aspirin if the P2Y12 receptor antagonist is interrupted (strong recommendation, moderate quality evidence). P2Y12 receptor antagonist therapy should be reinstated within 5 days (strong recommendation, moderate quality evidence).

Dual antiplatelet therapy (DAPT) is prescribed for patients with acute coronary artery syndromes, and those with coronary artery stents and is generally recommended for 12 months following placement of drug-eluting coronary stents. Occasionally, bare metal coronary stents are sited, and DAPT is recommended for 1 month, though aspirin is continued long term for both types of stents. Acute GI bleeding during DAPT is a high-risk situation, and the imperative, after adequate resuscitation, is to achieve haemostasis within the GI tract. Patients who develop LGIB while receiving DAPT have a fivefold increase in rebleeding. ${ }^{112}$ In patients on DAPT with coronary stents it would be preferable to continue treatment owing to the risk of stent thrombosis, and liaison should occur with a senior cardiologist in the emergency setting. Patients with other vascular stents should also be discussed with the responsible treating physician, surgeon or interventional radiologist.

In the event of severe LGIB it may be necessary to temporarily discontinue antiplatelet therapy, but this should be limited to clopidogrel (or other P2Y12 inhibitor), and aspirin continued. The P2Y12 inhibitor should be restarted within 5 days at a maximum owing to the high risk of thrombosis after this time. This timeframe is based on a large number of studies of discontinuation of antiplatelet therapy in patients with drug-eluting stents, and represents an optimal balance between haemorrhage and thrombosis, ${ }^{119}$ though it has not been tested prospectively. 
If antithrombotic therapy is withheld, the timing of restarting it after LGIB is determined by the risk of rebleeding versus the risk of acute thrombosis without antithrombotic therapy. There are no randomised studies on the timing of reintroduction of antithrombotic therapy for LGIB in the immediate inpatient setting. A cohort study by Chan et al compared patients who continued long-term aspirin after admission with LGIB, versus those who discontinued it. The latter group had fewer rebleeding events, but significantly more cardiovascular events and deaths. ${ }^{104}$ This is in keeping with the cohort study by Oakland et al on a short interruption of antiplatelet therapy. ${ }^{112}$

14. We recommend interrupting direct oral anticoagulant therapy at presentation (strong recommendation, low quality evidence). We recommend considering treatment with inhibitors such as idarucizumab or andexanet for life-threatening haemorrhage on direct oral anticoagulants (strong recommendation, moderate quality evidence). We suggest restarting DOAC treatment at a maximum of 7 days after haemorrhage (weak recommendation, very low quality evidence).

DOACs have a rapid onset of action, and full anticoagulant activity is established within 3 hours of the first dose. They have relatively short half-lives, but these will be prolonged in renal failure, particularly for dabigatran. In most cases of LGIB it is sufficient to withhold the drug, resuscitate the patient and wait for the anticoagulant effects to dissipate. ${ }^{112}$ Severe GI bleeding with DOACs is challenging to manage and advice should be sought from a haematologist. Vitamin K, FFP or protamine sulfate are ineffective. Prothrombin complex concentrate reverses the anticoagulant effect of rivaroxaban, but not dabigatran, in healthy volunteers ${ }^{120}$ but this has not been tested in acute GI bleeding. Haemodialysis might be of some benefit in dabigatran patients with severe life-threatening haemorrhage. Fortunately, an antidote for dabigatran, idarucizumab, ${ }^{121}$ is now licensed for this situation, and adexanet is available for the anti-factor Xa inhibitors. ${ }^{122}$ Other antidotes are in development. ${ }^{122} 123$

DOAC reintroduction will result in rapid re-anticoagulation, and this should be considered when planning the timing of this. Patients with a history of atrial fibrillation will be at relatively low risk of thrombosis after temporary DOAC discontinuation but this may be greater in a patient who has had a recent stroke. Restarting DOAC at 7 days after haemorrhage would seem reasonable in most cases based on experience with warfarin. In a patient at high risk of rebleeding, anticoagulation with warfarin may be preferable to DOAC therapy owing to the more effective and rapid reversal of anticoagulation that is possible with warfarin. Patients who develop LGIB while receiving antiplatelet or anticoagulant drugs may have valid concerns about interrupting these drugs. Where there is clinical equipoise about this, the lead clinician for GI bleeding should liaise with the clinician who has initiated this treatment.

\section{Antifibrinolytic drugs}

Tranexamic acid improves mortality from trauma when given intravenously in the acute setting, ${ }^{124}$ and has therefore been incorporated into the massive transfusion protocols in many hospitals. There is some evidence for its benefit in acute GI bleeding. Several trials of tranexamic acid in UGIB have been carried out, ${ }^{125}$ which on pooled analysis showed a $40 \%$ risk reduction in mortality. ${ }^{126}$ However, this treatment benefit for mortality was no longer apparent when the analysis was limited to trials at low risk of bias. Furthermore, the studies were considered historic and before the routine use of high-dose acid suppression and endoscopic therapy, and thus their extrapolation to modern day care is uncertain. Studies have been too small to assess the effect of tranexamic acid on thromboembolic events in the context of GI bleeding. At this time we suggest that use of tranexamic acid in acute LGIB is confined to clinical trials, pending the results of the HALT-IT trial. ${ }^{127}$

\section{Organisation of services}

15. All hospitals should have a GI bleeding lead and agreed pathways for the management of acute LGIB (good practice statement).

16. We recommend that all hospitals that routinely admit patients with LGIB should have access to 7/7 on-site colonoscopy and the facilities to provide endoscopic therapy (good practice statement).

17. We recommend that all hospitals that routinely admit patients with LGIB should have access to 24/7 interventional radiology either on site, or via a formalised referral pathway to another hospital (good practice statement).

The 2015 NCEPOD report recommended that 'the traditional separation of care for GI bleeding in hospitals should stop'. All acute hospitals should have a lead clinician who is responsible for local integrated care pathways for both upper and lower GI bleeding and their clinical governance, including identifying named consultants, ideally gastroenterologists, who would be responsible for the emergency and ongoing care of all major GI bleeds. ${ }^{5}$ Given the complexity of care required by this heterogeneous group of patients, we support this recommendation; however, it is realised that many local factors exist that will not make the same model of care suitable for all hospitals. It is strongly recommended that every hospital has a clinical lead for gastrointestinal bleeding who is responsible for the integrated implementation of care and the monitoring of key performance indicators.

In their 2015 report, NCEPOD recommended that 'patients with any acute GI bleed should only be admitted to hospitals with 24/7 access to on-site endoscopy, IR (on site or covered by a formal network), on-site abdominal surgery, on-site critical care and anaesthesia. ${ }^{5}$ The provision of these services requires the availability of appropriately trained staff and specialist equipment. The 2015 national LGIB audit examined organisational compliance with this standard, finding that $73 \%$ hospitals were able to provide 24/7 access to lower GI endoscopy, 55\% 24/7 on-site or networked IR and 99\% critical care and emergency abdominal surgery. ${ }^{4}$

\section{Lower GI endoscopy}

In this guideline, we recommend that patients with major bleeding should undergo inpatient colonoscopy on the next available list. The 2015 audit found that only 57\% hospitals had defined emergency slots on their endoscopy lists that could be used for LGIB. ${ }^{4}$ Endoscopy departments may therefore need to consider the extra capacity required to support this recommendation. Evidence does not support the need to routinely perform colonoscopy for LGIB within 12 or 24 hours; however, it may be appropriate to occasionally perform colonoscopy with a view to providing treatment over a weekend rather than waiting for the next available service list.

\section{Interventional radiology (IR)}

Nationally there is considerable variation in the provision of IR, ranging from 24/7 on-site access to 'no arrangements in place.' A retrospective review of 99415 hospitalisations for diverticular 
LGIB found that the need to transfer was independently associated with mortality. ${ }^{128}$ Hospitals without $24 / 7$ on-site IR should therefore have a formalised referral pathway to another provider, with details of the specialty of the receiving team and patient transfer services.

\section{Surgery}

In the UK mortality from laparotomy is between 3.6\% and $41.7 \%$, and consultant presence in theatre varies. ${ }^{129}$ Acute care surgery models as well as centralised units and hospitals with dedicated emergency operating rooms, access to radiology and intensive care facilities are all factors associated with improved clinical and financial outcomes in the delivery of emergency general surgery. There is, however, no consensus on the elements that constitute an ideal acute care surgery model and how it can be introduced into current surgical practice. ${ }^{130}$

\section{COST EFFECTIVENESS}

The treatment algorithm proposed in this guideline (figure 1) focuses the use of resources towards unstable patients. In the national audit, shocked patients accounted for only $2.3 \%$ of all admissions. ${ }^{6}$ Early intervention is cost effective as it is likely to be associated with reduced need for supportive treatments, such as $\mathrm{RBC}$ transfusion and a reduced 1 length of stay.

We recommend that patients with major bleeding receive colonoscopy on the next available inpatient list. Currently, only $25 \%$ of admitted patients undergo lower GI endoscopy and a further $30 \%$ will have an outpatient flexible sigmoidoscopy or colonoscopy. ${ }^{6}$ The national incidence of LGIB requiring hospital admission is estimated to be 21120 cases a year. ${ }^{6}$ Performing lower GI endoscopy on the $45 \%$ of these who are not currently receiving these interventions will equate to an additional 9500 lower GI endoscopies nationally, or 66 per NHS hospital per year, or five per month. This additional cost should be offset by the increased identification of patients who do not need acute admission. In the national audit, the average length of stay of patients with an Oakland score $\leq 8$ was 4 days. ${ }^{22}$ An additional cost saving can be made by avoiding unnecessary transfusion, which accounts for as many as $80 \%$ of RBC transfusions. ${ }^{4}$

\section{Key performance indicators}

Both the NECPOD report and NHSBT audit found deficiencies in the provision of 24/7 colonoscopy and IR. ${ }^{45}$ Hospitals that routinely admit patients with LGIB should audit their access to upper and lower GI endoscopy, CTA, catheter angiography and embolisation, particularly in the out of hours setting. Key performance indicators should also include waiting times for inpatient colonoscopy and flexible sigmoidoscopy and the length of time between performance of CTA and catheter angiography. A case review of any patient proceeding to laparotomy for haemorrhage control should be undertaken, focusing on the use and findings of preoperative diagnostics to establish whether surgery might have been avoided.

Given the high proportion of RBC transfusions in patients with LGIB that may be deemed inappropriate, ${ }^{4}$ all hospitals should regularly audit the use of blood transfusion, including the appropriateness of $\mathrm{Hb}$ triggers, thresholds and volume of blood transfusions. All patients who are unstable, or meet the criteria for a major bleed should have a rebleed plan documented in their medical notes. This should be audited regularly.

\section{LIMITATIONS}

The evidence base for the management of LGIB is incomplete and inferior compared with that which is available for UGIB. In particular, there are few RCTs comparing approaches to diagnosis or management. Using GRADE methodology many of our recommendations are STRONG despite WEAK evidence. It is worth considering the criteria that GRADE advises for a 'strong recommendation'. From a clinician's perspective a STRONG recommendation implies that 'most patients should receive the recommended course of action'. ${ }^{17}$ From a patient's perspective, 'most people in your situation would want the recommended course of action and only a small proportion would not'. ${ }^{17}$ GRADE permits strong recommendations to be made when the quality of evidence is low if there is a suggestion of benefit in a life-threatening situation. ${ }^{131}$ We believe that the guideline recommends prompt and accurate diagnosis and management, fulfilling these criteria despite the quality of empirical evidence available for investigation of such a difficult subject.

\section{CONCLUSIONS AND SUGGESTIONS FOR FUTURE RESEARCH}

Future research should compare the efficacy of mesenteric embolisation with endoscopic therapy in major bleeds, as a priority. There is a lack of RCTs comparing haemostatic techniques in the colon, limiting the recommendations that can be made in this guideline. Studies that do exist tend not to include Western populations. This gap in the evidence base should be addressed. To aid initial assessment of bleed severity, we recommend the use of the Oakland score as a method of predicting clinical risk. This score was developed from one of the largest prospective databases of LGIB and externally validated, but has not been further validated beyond a study environment. Further external validation studies should be undertaken, and as the score has a high specificity, some patients who might be safely discharged immediately, may currently be identified as requiring admission. Further studies to determine the optimal score threshold for safe discharge are required. In the future the ideal risk score would be valid in both upper and lower GI bleeding, to enable coordination of care. As such, the development of a unifying risk score should be a research priority. Similarly, further iterations of this guideline should include both upper and lower GI bleeding in order to discourage the separation of these patients in the future. Increasing numbers of patients are receiving combination antiplatelet therapy or DOACs. No data are available on the optimum time to restart these medications should they be stopped, and studies to answer this question are urgently required.

\section{Author affiliations}

${ }^{1}$ London Digestive Centre, HCA Healthcare UK, London, UK

${ }^{2}$ Clinical Effectiveness Unit, Royal College of Surgeons, London, UK

${ }^{3}$ Translational Gastroenterology Unit, Experimental Medicine Division, Nuffield

Department of Clinical Medicine, John Radcliffe Hospital, Oxford, UK

${ }^{4}$ Department of Colorectal Surgery, Oxford University Hospitals NHS Foundation

Trust, Oxford, UK

${ }^{5}$ St Mark's Hospital, London, UK

${ }^{6}$ Robarts Clinical Trials, Inc., London, Ontario, Canada

${ }^{7}$ Medicine and Epidemiology and Biostatistics, University of Western Ontario, London, Ontario, Canada

${ }^{8}$ Department of Radiology, Leeds General Infirmary, Leeds, UK

${ }^{9}$ Department of Gastroenterology, Hutt Valley District Health Board, Lower Hutt, New Zealand

${ }^{10}$ Gastroenterology, Glasgow Royal Infirmary, Glasgow, UK

${ }^{11} \mathrm{NHS}$ Blood and Transplant, Oxford, UK

${ }^{12}$ Division of Gastroenterology, Ulster Hospital, Dundonald, UK

${ }^{13}$ Department of Interventional Radiology, Oxford University Hospitals NHS

Foundation Trust, Oxford, UK

${ }^{14}$ Gastroenterology, New Cross Hospital, Wolverhampton, UK 
${ }^{15}$ Department of Colorectal Surgery, Addenbrooke's Hospital, Cambridge, UK

${ }^{16}$ British Society of Gastroenterology, London, UK

${ }^{17}$ Department of Surgery and Cancer, Imperial College, London, UK

Acknowledgements We thank our colleague Carolyn Doree (NHS Blood and Transplant) for designing the literature review search strategy.

Contributors Working subgroups with specific areas of expertise were formed to critically appraise the literature supporting the following areas of clinical management: initial assessment, risk stratification and resuscitation (KO, VJ, MFM); medical management (AMV); diagnostic and therapeutic radiology (RU, SM); the exclusion of upper gastrointestinal bleeding and capsule endoscopy (MM); colonoscopy (AH, JEE, AJM); surgery (RG, JW). KO created the first draft of the guideline and all authors critically revised the paper.

Funding KO was supported by funding from NHS Blood and Transplant, Bowel Disease Research Foundation and a research fellowship from the Royal College of Surgeons of England. JEE was supported by the National Institute for Health Research (NIHR) Oxford Biomedical Research Centre (BRC).

Disclaimer The views expressed are those of the author(s) and not necessarily those of the NHS, the NIHR or the Department of Health.

Competing interests JEE is a member of the Clinical Advisory Board for Lumend and has received support for departmental research from Olympus; AJM participates in training courses and is on the advisory boards for Cook, Boston Scientific, Vifor, Ferring, Shire and Abbvie; AMV has received fees from Olympus for educational presentations; MFM is on the editorial board for Transfusion Medicine Reviews for which he receives an annual fee and $\mathrm{KO}$ has received editorial fees for reviews on the same topic

\section{Patient consent for publication Not required.}

Provenance and peer review Not commissioned; externally peer reviewed.

Open access This is an open access article distributed in accordance with the Creative Commons Attribution Non Commercial (CC BY-NC 4.0) license, which permits others to distribute, remix, adapt, build upon this work non-commercially, and license their derivative works on different terms, provided the original work is properly cited, appropriate credit is given, any changes made indicated, and the use is non-commercial. See: http://creativecommons.org/licenses/by-nc/4.0/.

\section{REFERENCES}

1 Lanas A, García-Rodríguez LA, Polo-Tomás M, et al. Time trends and impact of upper and lower gastrointestinal bleeding and perforation in clinical practice. Am J Gastroenterol 2009;104:1633-41.

2 Hreinsson JP, Gumundsson S, Kalaitzakis E, et al. Lower gastrointestinal bleeding: incidence, etiology, and outcomes in a population-based setting. Eur J Gastroenterol Hepatol 2013:25:37-43.

3 Newman J, Fitzgerald JE, Gupta S, et al. Outcome predictors in acute surgical admissions for lower gastrointestinal bleeding. Colorectal Dis 2012;14:1020-6.

4 National Comparative Audit of Blood Transfusion. National comparative audit of lower gastrointestinal bleeding and the use of blood. 2016. www.hospital.blood.co. uk

5 National Confidential Enquiry into Patient Outcomes and Death. Time to get control? National Confidential Enquiry into Patient Outcomes and Death. 2015. www. ncepod.org.uk

6 Oakland K, Guy R, Uberoi R, et al. Acute lower GI bleeding in the UK: patient characteristics, interventions and outcomes in the first nationwide audit. Gut 2018;67:654-62.

7 Strate LL, Ayanian JZ, Kotler G, et al. Risk factors for mortality in lower intestinal bleeding. Clin Gastroenterol Hepatol 2008:6:1004-10. quiz 955.

8 Wheat CL, Strate LL. Trends in hospitalization for diverticulitis and diverticular bleeding in the United States From 2000 to 2010. Clin Gastroenterol Hepatol 2016;14:96-103.

9 Strate LL, Orav EJ, Syngal S. Early predictors of severity in acute lower intestinal tract bleeding. Arch Intern Med 2003;163:838-43.

10 Carson JL, Guyatt G, Heddle NM, et al. Clinical practice guidelines from the AABB red blood cell transfusion thresholds and storage. JAMA 2016;316:2025-35.

11 Köhler G, Koch 00, Antoniou SA, et al. Relevance of surgery after embolization of gastrointestinal and abdominal hemorrhage. World J Surg 2014:38:2258-66.

12 Ozdil B, Akkiz H, Sandikci M, et al. Massive lower gastrointestinal hemorrhage secondary to rectal hemorrhoids in elderly patients receiving anticoagulant therapy: case series. Dig Dis Sci 2010;55:2693-4.

13 Hochter W, Weingart J, Kuhner W, et al. Angiodysplasia in the colon and rectum. Endoscopic morphology, localisation and frequency. Endoscopy 1985;17:182-5.

14 Brouwers MC, Kerkvliet K, Spithoff K. AGREE Next Steps Consortium. The AGREE Reporting Checklist: a tool to improve reporting of clinical practice guidelines. BMJ 2016;352:i1152.

15 Tham TC, Gleeson D, Greenfield SM, et al. British Society of Gastroenterology policy and processes for the development of guidelines. Gut 2015;64:1184-5.
16 Oxford Centre for Evidence Based Medicine. Levels of evidence. Oxford University. 2009. https://www.cebm.net/2009/06/oxford-centre-evidence-based-medicinelevels-evidence-march-2009/

17 Atkins D, Best D, Briss PA, et al. Grading quality of evidence and strength of recommendations. BMJ 2004;328:1490.

18 Olaussen A, Blackburn T, Mitra B, et al. Review article: shock index for prediction of critical bleeding post-trauma: a systematic review. Emerg Med Australas 2014; $26: 223-8$

19 Rossaint R, Bouillon B, Cerny V, et al. The European guideline on management of major bleeding and coagulopathy following trauma: fourth edition. Crit Care 2016:20:100.

20 Rassameehiran S, Teerakanok J, Suchartlikitwong S, et al. Utility of the shock index for risk stratification in patients with acute upper gastrointestinal bleeding. South Med J 2017;110:738-43

21 Nakasone Y, Ikeda O, Yamashita Y, et al. Shock index correlates with extravasation on angiographs of gastrointestinal hemorrhage: a logistics regression analysis. Cardiovasc Intervent Radiol 2007:30:861-5.

22 Oakland K, Jairath V, Uberoi R, et al. Derivation and validation of a novel risk score for safe discharge after acute lower gastrointestinal bleeding: a modelling study. Lancet Gastroenterol Hepatol 2017;2:635-43.

23 Blatchford O, Murray WR, Blatchford M. A risk score to predict need for treatment for upper gastrointestinal haemorrhage. The Lancet 2000;356:1318-21.

24 Oakland K, Isherwood J, Lahiff C, et al. Diagnostic and therapeutic treatment modalities for acute lower gastrointestinal bleeding: a systematic review. Endosc Int Open 2017; 5:E959-73

25 National Institute for Health and Care Excellence. Guideline NG12: Suspected cancer: recognition and referral. 2015 www.nice.org.uk

26 Pasha SF, Shergill A, Acosta RD, et al. The role of endoscopy in the patient with lowe Gl bleeding. Gastrointest Endosc 2014;79:875-85.

27 Strate LL, Gralnek IM. ACG clinical guideline: management of patients with acute lower gastrointestinal bleeding. Am J Gastroenterol 2016;111:755.

28 Niikura R, Nagata N, Shimbo T, et al. Adverse events during bowel preparation and colonoscopy in patients with acute lower gastrointestinal bleeding compared with elective non-gastrointestinal bleeding. PLoS One 2015;10:e0138000.

29 Green BT, Rockey DC, Portwood G, et al. Urgent colonoscopy for evaluation and management of acute lower gastrointestinal hemorrhage: a randomized controlled trial. Am J Gastroenterol 2005;100:2395-402.

30 Laine L, Shah A. Randomized trial of urgent vs. elective colonoscopy in patients hospitalized with lower GI bleeding. Am J Gastroenterol 2010;105:2636-41. quiz 42.

31 Jensen DM, Machicado GA, Jutabha R, et al. Urgent colonoscopy for the diagnosis and treatment of severe diverticular hemorrhage. N Engl J Med Overseas Ed 2000;342:78-82.

32 Strate LL, Syngal S. Timing of colonoscopy: impact on length of hospital stay in patients with acute lower intestinal bleeding. Am J Gastroenterol 2003:98:317-22

33 Nagata N, Niikura R, Sakurai T, et al. Safety and effectiveness of early colonoscopy in management of acute lower gastrointestinal bleeding on the basis of propensity score matching analysis. Clin Gastroenterol Hepatol 2016;14:558-64.

34 Nagata N, Niikura R, Aoki T, et al. Role of urgent contrast-enhanced multidetector computed tomography for acute lower gastrointestinal bleeding in patients undergoing early colonoscopy. J Gastroentero/ 2015;50:1162-72.

35 Rodriguez-Moranta F, Berrozpe A, Botargues JM, et al. Colonoscopy delay in lower gastrointestinal bleeding: influence on diagnostic accuracy, endoscopic therapy and hospital stay. Gastrointest Endosc 2007:65:AB261.

36 Schmulewitz N, Fisher DA, Rockey DC. Early colonoscopy for acute lower GI bleeding predicts shorter hospital stay: a retrospective study of experience in a single center. Gastrointest Endosc 2003;58:841-6.

37 Navaneethan U, Njei B, Venkatesh PG, et al. Timing of colonoscopy and outcomes in patients with lower GI bleeding: a nationwide population-based study. Gastrointest Endosc 2014;79:297-306. e12.

38 Albeldawi M, Ha D, Mehta P, et al. Utility of urgent colonoscopy in acute lower gastro-intestinal bleeding: a single-center experience. Gastroenterol Rep 2014;2:300-5.

39 Smoot RL, Gostout CJ, Rajan E, et al. Is early colonoscopy after admission for acute diverticular bleeding needed? Am J Gastroentero/ 2003:98:1996-9.

40 Lim DS, Kim HG, Jeon SR, et al. Comparison of clinical effectiveness of the emergent colonoscopy in patients with hematochezia according to the type of bowel preparation. J Gastroenterol Hepatol 2013;28:1733-7.

41 Kennedy DW, Laing CJ, Tseng LH, et al. Detection of active gastrointestinal hemorrhage with CT angiography: a 4(1/2)-year retrospective review. J Vasc Interv Radiol 2010:21:848-55.

42 Ren JZ, Zhang MF, Rong AM, et al. Lower gastrointestinal bleeding: role of 64-row computed tomographic angiography in diagnosis and therapeutic planning. World J Gastroenterol 2015:21:4030-7.

43 Dobritz M, Engels HP, Schneider A, et al. Evaluation of dual-phase multi-detectorrow CT for detection of intestinal bleeding using an experimental bowel model. Eur Radiol 2009; 19:875-81 
44 Ernst O, Bulois P, Saint-Drenant S, et al. Helical CT in acute lower gastrointestinal bleeding. Eur Radiol 2003;13:114-7.

45 Foley PT, Ganeshan A, Anthony S, et al. Multi-detector CT angiography for lower gastrointestinal bleeding: can it select patients for endovascular intervention? J Med Imaging Radiat Oncol 2010;54:9-16.

46 Abbas SM, Bissett IP, Holden A, et al. Clinical variables associated with positive angiographic localization of lower gastrointestinal bleeding. ANZ J Surg 2005;75:953-7.

47 Radiologists TRCo. Standards for intravascular contrast administration to adult patients, 2015

48 Jensen DM, Machicado GA. Diagnosis and treatment of severe hematochezia. The role of urgent colonoscopy after purge. Gastroenterology 1988;95:1569-74.

49 Srygley FD, Gerardo CJ, Tran T, et al. Does this patient have a severe upper gastrointestinal bleed? JAMA 2012;307:1072-9.

50 Huang ES, Karsan S, Kanwal F, et al. Impact of nasogastric lavage on outcomes in acute GI bleeding. Gastrointest Endosc 2011;74:971-80.

51 Rockey DC, Ahn C, de Melo SW. Randomized pragmatic trial of nasogastric tube placement in patients with upper gastrointestinal tract bleeding. J Investig Med 2017:65:759-64

52 Chung M, Dubel GJ, Noto RB, et al. Acute lower gastrointestinal bleeding: temporal factors associated with positive findings on catheter angiography after ${ }^{99 \mathrm{~m}} \mathrm{Tc}$-labeled RBC scanning. AJR Am J Roentgenol 2016;207:170-6.

53 Koh FH, Soong J, Lieske B, et al. Does the timing of an invasive mesenteric angiography following a positive CT mesenteric angiography make a difference? Int J Colorectal Dis 2015;30:57-61.

54 TRCo R. Standards of practice and guidance for trauma radiology in severely injured patients. (Second issue).

55 National Institute for Health and Care Excellence. Major trauma: assessment and initial management. 2016 www.nice.org.uk.

56 Jacovides CL, Nadolski G, Allen SR, et al. Arteriography for lower gastrointestinal hemorrhage: role of preceding abdominal computed tomographic angiogram in diagnosis and localization. JAMA Surg 2015;150:650-6.

57 Khan O, Singh P, Archibald A, et al. The role of labelled red blood cell scintigraphy in the detection of acute gastrointestinal bleeding. West Indian Med J 2000;49:298-301.

58 Gutierrez C, Mariano M, Vander Laan T, et al. The use of technetium-labeled erythrocyte scintigraphy in the evaluation and treatment of lower gastrointestinal hemorrhage. Am Surg 1998;64:989-92.

59 O'Neill BB, Gosnell JE, Lull RJ, et al. Cinematic nuclear scintigraphy reliably directs surgical intervention for patients with gastrointestinal bleeding. Arch Surg 2000;135:1076-81. discussion 81-2.

60 Rondonotti E, Villa F, Mulder CJ, et al. Small bowel capsule endoscopy in 2007: indications, risks and limitations. World J Gastroenterol 2007;13:6140-9.

61 Leung WK, Ho SS, Suen BY, et al. Capsule endoscopy or angiography in patients with acute overt obscure gastrointestinal bleeding: a prospective randomized study with long-term follow-up. Am J Gastroenterol 2012;107:1370-6.

62 Laine L, Sahota A, Shah A. Does capsule endoscopy improve outcomes in obscure gastrointestinal bleeding? Randomized trial versus dedicated small bowel radiography. Gastroenterology 2010;138:1673-80. e1; quiz e11-2.

63 Segarajasingam DS, Hanley SC, Barkun AN, et al. Randomized controlled trial comparing outcomes of video capsule endoscopy with push enteroscopy in obscure gastrointestinal bleeding. Can J Gastroenterol Hepatol 2015;29:85-90.

64 Heo HM, Park CH, Lim JS, et al. The role of capsule endoscopy after negative $\mathrm{CT}$ enterography in patients with obscure gastrointestinal bleeding. Eur Radiol 2012:22:1159-66.

65 Carey EJ, Leighton JA, Heigh RI, et al. A single-center experience of 260 consecutive patients undergoing capsule endoscopy for obscure gastrointestinal bleeding. Am J Gastroenterol 2007;102:89-95.

66 Saperas E, Dot J, Videla S, et al. Capsule endoscopy versus computed tomographic or standard angiography for the diagnosis of obscure gastrointestinal bleeding. Am J Gastroenterol 2007:102:731-7.

67 Redondo-Cerezo E, Pérez-Vigara G, Pérez-Sola A, et al. Diagnostic yield and impact of capsule endoscopy on management of patients with gastrointestinal bleeding of obscure origin. Dig Dis Sci 2007;52:1376-81.

68 Chami G, Raza M, Bernstein CN. Usefulness and impact on management of positive and negative capsule endoscopy. Can J Gastroenterol 2007;21:577-81.

69 Goenka MK, Majumder S, Kumar S, et al. Single center experience of capsule endoscopy in patients with obscure gastrointestinal bleeding. World I Gastroenterol 2011;17:774-8.

70 Apostolopoulos P, Liatsos C, Gralnek IM, et al. Evaluation of capsule endoscopy in active, mild-to-moderate, overt, obscure GI bleeding. Gastrointest Endosc 2007:66:1174-81.

71 Singh A, Marshall C, Chaudhuri B, et al. Timing of video capsule endoscopy relative to overt obscure GI bleeding: implications from a retrospective study. Gastrointest Endosc 2013;77:761-6.

72 Gerson LB, Fidler JL, Cave DR, et al. ACG clinical guideline: diagnosis and management of small bowel bleeding. Am J Gastroenterol 2015;110:1265-87. quiz 88.
73 Rezapour M, Amadi C, Gerson LB. Retention associated with video capsule endoscopy: systematic review and meta-analysis. Gastrointest Endosc 2017:85:1157-68.

74 Strate LL, Naumann CR. The role of colonoscopy and radiological procedures in the management of acute lower intestinal bleeding. Clin Gastroenterol Hepatol 2010:8:333-43. quiz e44.

75 Wedi E, von Renteln D, Jung C, et al. Treatment of acute colonic diverticular bleeding in high risk patients, using an over-the-scope clip: a case series. Endoscopy 2016;48(S 01):E383-5.

76 Hashimoto R, Hamamoto H, Tanuma T. Endoscopic hemostasis of diverticular bleeding by using detachable snares. Gastrointest Endosc 2016;84:379-80.

77 Setoyama T, Ishii N, Fujita Y. Enodoscopic band ligation (EBL) is superior to endoscopic clipping for the treatment of colonic diverticular hemorrhage. Surg Endosc 2011;25:3574-8

78 Kaltenbach T, Watson R, Shah J, et al. Colonoscopy with clipping is useful in the diagnosis and treatment of diverticular bleeding. Clin Gastroenterol Hepatol 2012;10:131-7.

79 Pittayanon R, Rerknimitr R, Barkun A. Prognostic factors affecting outcomes in patients with malignant $\mathrm{GI}$ bleeding treated with a novel endoscopically delivered hemostatic powder. Gastrointest Endosc 2018;87:994-1002.

80 Bloomfeld RS, Rockey DC, Shetzline MA. Endoscopic therapy of acute diverticular hemorrhage. Am J Gastroenterol 2001;96:2367-72.

81 Kwan V, Bourke MJ, Williams SJ, et al. Argon plasma coagulation in the management of symptomatic gastrointestinal vascular lesions: experience in 100 consecutive patients with long-term follow-up. Am J Gastroenterol 2006;101:58-63.

82 Olmos JA, Marcolongo M, Pogorelsky V, et al. Long-term outcome of argon plasma ablation therapy for bleeding in 100 consecutive patients with colonic angiodysplasia. Dis Colon Rectum 2006;49:1507-16.

83 Funaki B, Kostelic JK, Lorenz J, et al. Superselective microcoil embolization of colonic hemorrhage. AJR Am J Roentgenol 2001;177:829-36.

84 Waugh J, Madan A, Sacharias N, et al. Embolization for major lower gastrointestinal haemorrhage: five-year experience. Australas Radiol 2004;48:311-7.

85 Chan DK, Soong J, Koh F, et al. Predictors for outcomes after super-selective mesenteric embolization for lower gastrointestinal tract bleeding. ANZ J Surg 2016;86:459-63.

86 DeBarros J, Rosas L, Cohen J, et al. The changing paradigm for the treatment of colonic hemorrhage: superselective angiographic embolization. Dis Colon Rectum 2002:45:802-8

87 Rossetti A, Buchs NC, Breguet R, et al. Transarterial embolization in acute colonic bleeding: review of 11 years of experience and long-term results. Int J Colorectal Dis 2013:28:777-82

88 Bandi R, Shetty PC, Sharma RP, et al. Superselective arterial embolization for the treatment of lower gastrointestinal hemorrhage. J Vasc Interv Radiol 2001;12:1399-405.

89 Tan KK, Strong DH, Shore T, et al. The safety and efficacy of mesenteric embolization in the management of acute lower gastrointestinal hemorrhage. Ann Coloproctol 2013:29:205-8

90 Yap FY, Omene BO, Patel MN, et al. Transcatheter embolotherapy for gastrointestinal bleeding: a single center review of safety, efficacy, and clinical outcomes. Dig Dis SC 2013;58:1976-84.

91 Adusumilli S, Gosselink MP, Ctercteko G, et al. The efficacy of selective arterial embolization in the management of colonic bleeding. Tech Coloproctol 2014;18:529-33.

92 Tan KK, Nallathamby V, Wong D, et al. Can superselective embolization be definitive for colonic diverticular hemorrhage? An institution's experience over 9 years. $J$ Gastrointest Surg 2010;14:112-8

93 Tandberg DJ, Smith TP, Suhocki PV, et al. Early outcomes of empiric embolization of tumor-related gastrointestinal hemorrhage in patients with advanced malignancy. J Vasc Interv Radiol 2012;23:1445-52.

94 Plummer JM, Gibson TN, Mitchell DI, et al. Emergency subtotal colectomy for lower gastrointestinal haemorrhage: over-utilised or under-estimated? Int J Clin Pract 2009;63:865-8

95 Padhi S, Kemmis-Betty S, Rajesh S, et al. Blood transfusion: summary of NICE guidance. BMJ 2015;351:h5832.

96 Oakland K, Jairath V, Murphy MF. Advances in transfusion medicine: gastrointestinal bleeding. Transfus Med 2018;28:132-9.

97 Villanueva C, Colomo A, Bosch A, et al. Transfusion strategies for acute upper gastrointestinal bleeding. N Engl J Med Overseas Ed 2013;368:11-21.

98 Jairath V, Kahan BC, Gray A, et al. Restrictive versus liberal blood transfusion for acute upper gastrointestinal bleeding (TRIGGER): a pragmatic, open-label, cluster randomised feasibility trial. Lancet 2015;386:137-44.

99 Odutayo A, Desborough MJ, Trivella M, et al. Restrictive versus liberal blood transfusion for gastrointestinal bleeding: a systematic review and meta-analysis of randomised controlled trials. Lancet Gastroenterol Hepatol 2017:2:354-60.

100 Docherty AB, O'Donnell R, Brunskill S, et al. Effect of restrictive versus liberal transfusion strategies on outcomes in patients with cardiovascular disease in a noncardiac surgery setting: systematic review and meta-analysis. BMJ 2016;352:11351. 
101 National Institute for Health and Care Excellence. Guideline NG24: Blood transfusion. 2015 www.nice.org.uk

102 Noddeland H, Töllöfsrud S, Svennevig J, et al. Universal solvent/detergent-treated fresh frozen plasma (Uniplas-rationale and clinical properties. Thromb Res 2002;107(Suppl 1):S33-7

103 Doussau A, Perez P, Puntous M, et al. Fresh-frozen plasma transfusion did not reduce 30-day mortality in patients undergoing cardiopulmonary bypass cardiac surgery with excessive bleeding: the PLASMACARD multicenter cohort study. Transfusion 2014; 54:1114-24

104 Chan FK, Leung Ki EL, Wong GL, et al. Risks of bleeding recurrence and cardiovascular events with continued aspirin use after lower gastrointestinal hemorrhage. Gastroenterology 2016;151:271-7.

105 Keeling D, Tait RC, Watson H. British Committee of Standards for Haematology. Perioperative management of anticoagulation and antiplatelet therapy. $\mathrm{Br} J$ Haematol 2016;175:602-13.

106 Qureshi W, Mittal C, Patsias I, et al. Restarting anticoagulation and outcomes after major gastrointestinal bleeding in atrial fibrillation. Am J Cardiol 2014;113:662-8.

107 Sengupta N, Feuerstein JD, Patwardhan VR, et al. The risks of thromboembolism vs. recurrent gastrointestinal bleeding after interruption of systemic anticoagulation in hospitalized inpatients with gastrointestinal bleeding: a prospective study. Am J Gastroentero/ 2015;110:328-35.

108 Staerk L, Lip GY, Olesen JB, et al. Stroke and recurrent haemorrhage associated with antithrombotic treatment after gastrointestinal bleeding in patients with atrial fibrillation: nationwide cohort study. BMJ 2015;351:h5876.

109 Beyer-Westendorf J, Gelbricht V, Förster K, et al. Peri-interventional management of novel oral anticoagulants in daily care: results from the prospective Dresden NOAC registry. Eur Heart J 2014;35:1888-96.

110 Douketis JD, Healey JS, Brueckmann $\mathrm{M}$, et al. Perioperative bridging anticoagulation during dabigatran or warfarin interruption among patients who had an elective surgery or procedure. Substudy of the RE-LY trial. Thromb Haemost 2015;113:625-32

111 Douketis JD, Spyropoulos AC, Kaatz S, et al. Perioperative bridging anticoagulation in patients with atrial fibrillation. N Engl J Med 2015;373:823-33.

112 Oakland K, Desborough MJ, Murphy MF, et al. Rebleeding and mortality after lower gastrointestinal bleeding in patients taking antiplatelets or anticoagulants. Clin Gastroenterol Hepatol 2017. pii: S1542-3565(17)31528-8. doi: 10.1016/j. cgh.2017.12.032. [Epub ahead of print].

113 Gralnek IM, Dumonceau JM, Kuipers EJ, et al. Diagnosis and management of nonvariceal upper gastrointestinal hemorrhage: European Society of Gastrointestina Endoscopy (ESGE) Guideline. Endoscopy 2015;47:a1-46.

114 Veitch AM, Vanbiervliet G, Gershlick AH, et al. Endoscopy in patients on antiplatelet or anticoagulant therapy, including direct oral anticoagulants: British Society of Gastroenterology (BSG) and European Society of Gastrointestinal Endoscopy (ESGE) guidelines. Endoscopy 2016;48:385-402.
115 Biondi-Zoccai GG, Lotrionte M, Agostoni P, et al. A systematic review and metaanalysis on the hazards of discontinuing or not adhering to aspirin among 50,279 patients at risk for coronary artery disease. Eur Heart J 2006;27:2667-74.

116 Maulaz AB, Bezerra DC, Michel P, et al. Effect of discontinuing aspirin therapy on the risk of brain ischemic stroke. Arch Neurol 2005;62:1217-20.

117 Oscarsson A, Gupta A, Fredrikson M, et al. To continue or discontinue aspirin in the perioperative period: a randomized, controlled clinical trial. Br J Anaesth 2010;104:305-12.

118 Sung JJ, Lau JY, Ching JY, et al. Continuation of low-dose aspirin therapy in peptic ulcer bleeding: a randomized trial. Ann Intern Med 2010;152:1-9.

119 Eisenberg MJ, Richard PR, Libersan D, et al. Safety of short-term discontinuation of antiplatelet therapy in patients with drug-eluting stents. Circulation 2009;119:1634-42.

120 Eerenberg ES, Kamphuisen PW, Sijpkens MK, et al. Reversal of rivaroxaban and dabigatran by prothrombin complex concentrate: a randomized, placebo-controlled, crossover study in healthy subjects. Circulation 2011;124:1573-9.

121 Pollack CV, Reilly PA, Eikelboom J, et al. Idarucizumab for dabigatran reversal. N Engl J Med 2015;373:511-20

122 Ansell JE, Bakhru SH, Laulicht BE, et al. Use of PER977 to reverse the anticoagulant effect of edoxaban. N Eng/ J Med 2014;371:2141-2.

123 Lu G, DeGuzman FR, Hollenbach SJ, et al. A specific antidote for reversal of anticoagulation by direct and indirect inhibitors of coagulation factor Xa. Nat Med 2013;19:446-51.

124 Shakur H, Roberts I, Bautista R, et al. Effects of tranexamic acid on death, vascular occlusive events, and blood transfusion in trauma patients with significant haemorrhage (CRASH-2): a randomised, placebo-controlled trial. Lancet 2010;376:23-32.

125 Gluud LL, Klingenberg SL, Langholz SE. Systematic review: tranexamic acid for upper gastrointestinal bleeding. Aliment Pharmacol Ther 2008;27:752-8.

126 Bennett C, Klingenberg SL, Langholz E, et al. Tranexamic acid for upper gastrointestinal bleeding. Cochrane Database Syst Rev 2014;4:CD006640.

127 Roberts I, Coats T, Edwards P, et al. HALT-IT-tranexamic acid for the treatment of gastrointestinal bleeding: study protocol for a randomised controlled trial. Tria/s 2014;15:450

128 Dao HE, Miller PE, Lee JH, et al. Transfer status is a risk factor for increased in-hospital mortality in patients with diverticular hemorrhage. Int J Colorectal Dis 2013:28:273-6.

129 Saunders DI, Murray D, Pichel AC, et al. Variations in mortality after emergency laparotomy: the first report of the UK Emergency Laparotomy Network. Br J Anaesth 2012;109:368-75.

130 Chana P, Burns EM, Arora S, et al. A systematic review of the impact of dedicated emergency surgical services on patient outcomes. Ann Surg 2016;263:20-7.

131 Andrews JC, Schünemann HJ, Oxman AD, et al. GRADE guidelines: 15. Going from evidence to recommendation-determinants of a recommendation's direction and strength. J Clin Epidemiol 2013;66:726-35. 